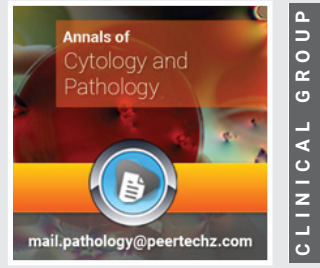

\title{
Vital Staining- Pivotal Role in the Field of Pathology
}

\author{
Nitya K ${ }^{1 *}$, Vikram S Amberkar ${ }^{2}$ and Bhuvaneshwari G Nadar ${ }^{3}$ \\ ${ }^{1}$ Assistant Professor, Department of Oral and Maxillofacial Pathology, Adhiparasakthi Dental College \\ and Hospital, Melmaruvathur, Tamil Nadu, India \\ ${ }^{2}$ Professor, Department of Oral and Maxillofacial Pathology, College of Dental Sciences, Davangere, \\ Karnataka, India
}

${ }^{3}$ Department of Preventive and Community Dentistry, Private Dental Practioner, Mumbai, India

Received: 27 April, 2020

Accepted: 11 June, 2020

Published: 12 June, 2020

*Corresponding author: Dr. Nitya K, Assistant Professor, Department of Oral and Maxillofacial Pathology, Adhiparasakthi Dental College and Hospital, Melmaruvathur, Tamil Nadu, India, Tel: 9962623510,8072448700;

E-mail: nitya.aytin@gmail.com

Keywords: Acetic acid; Dye; Intravital; Lugol's iodine; Malignancy; Methylene blue; Supravital; Toluidine blue; Rose bengal

https://www. peertechz.com

Check for updates

\section{Abstract}

A dye or stain is capable of penetrating the living cells or tissues and not inducing immediate degenerative changes. Vital stain means a stain that can be applied on a living cells without killing them. Thus these stains have been useful for both diagnostic and surgical techniques in a variety of medical specialities. As this technique is quite simple, easy to perform and cost effective, it can be useful in diagnosing any malignant changes occurring and also preventing them in a community level. Thus this vital staining can be used as an important tool in the field of diagnostic pathology. This article reviews about the various types of vital stains and its applications in the field of pathology.

\section{Introduction}

Oral cancer is the world's sixth most common malignancy and has one of the lowest survival rates, often due to late diagnosis. The most important determinant factor in cancer survival is diagnostic delay and it directly affects the survival rate [1].

Most oral cancers are preceded by precancerous lesions and early cancers that can be identified by visual inspection of the oral cavity.1Conventional oral examination is useful in the discovery of some oral lesions, but it does not identify all potentially premalignant lesions, as some are not readily apparent to visual inspection alone [2]. Adjunctive techniques have emerged that may facilitate early detection of oral premalignant and malignant lesions [3].

Thorough clinical examinations being one of the best modalities in suspecting the pathology, the biggest disadvantage in the diagnosis lies in detecting the site of biopsy and also whether biopsy is required or not in early lesions. Nowadays various diagnostic aids have been established in detecting such lesions but easy chair-side techniques can be used if possible. And one such technique is by using vital staining with dyes which is used for early recognition of lesion and also can improve the patient survival rate.
The vital dyes are auxiliary techniques used "in-vivo" in order to evidence suspicious lesions and/or to better define the lesion margins and extension. These stains are capable of penetrating living cells and binding to specific biological structures [4].

There are basically three ways in which we impart colour to tissues. They are

\section{Staining with dyes}

2. Impregnation with metallic salts.

3. The formation of coloured compounds in situ by means of chemical reactions.

Vital staining is included under the category of staining with dyes, is a procedure where living cells take up certain dyes, which selectively stain some elements in the cells, like mitochondria, lipid vesicles, lysosomes etc [4].

Vital staining are of two types: Intra vital staining and Supra vital staining. When the technique is applied in vivo, it is referred to as intravital staining.Eg: gastric mucosa and oral mucosa. If the technique is applied in vitro, i.e. living cells outside the body it is known as supravital staining. Eg. Leukocytes, nerve fibres and nerve endings. 
Thus this article gives a brief review on various dyes used in detecting oral lesions and their applications in the field of pathology.

\section{History}

An English anatomist named John Hunter in the eighteenth century first introduced vital staining. Most of the stains used for vital staining are dyes which are used in textile industry. These dyes are diluted to a large extent before they can be used on living tissue.

Principle: The principle behind vital staining is that particles of coloured matter are engulfed by macrophages [phagocytic cells]. The uptake of the dye may be because of phagocytosis and the coloured particle is seen within the cytoplasm of the cell [4].

\section{Classification [4]}

Intravital Staining

- Toluidine Blue

- Lugol's Iodine

- Methylene Blue

- $\quad$ Acetic Acid

- Rose Bengal

Supravital Staining

- DIOC for endoplasmic reticulum

- Janus green stain

- Rhoda mine 123

- Tryphan blue

- $\quad$ Nile red

\section{Applications [5]}

To determine the cell viability: Evans and Schulman noted that when leukocytes suspended in solution of tryphan blue, readily took up the dye upon mechanical injury. This is by supravital staining.

Chromoendoscopy: Is a procedure of using vital stains to identify abnormal mucosa. In patients who are at increased risk for squamous cell carcinoma, vital staining with lugol's iodine is performed at the time of upper endoscopy to aid in cancer detection, in such cases it is applied through spray catheter.

Here, the dye stains the glycogen in normal squamous epithelium a dark brown. Areas that are unstained particularly those that are larger than $5 \mathrm{~mm}$ are likely to be dysplastic / malignant and can be targeted for biopsy. This is an intravital staining, which is quick and easy to perform.

- To obtain cytological details of Protozoa.
- Used to stain various cell organelles - Janus Green stains cell mitochondria, DIOC ( 3,3 Dihexyloxa carbocyamine Iodide) is used stain endoplasmic reticulum as a fluroscent dye, Rhodamine 1,2,3 fluroscence for mitochondria.

- Used to stain various inclusions within the cell : Nile red fluroscence stains lipid vesicles.

- Nerve fibres: Using Methylene blue by Coers and Woolf which is a supravital staining.

\section{Toluidine blue (Tb)}

Discovered by William Henry Perkin in1856, after which it was primarily used in dye industry. The earliest technique of vital staining was developed by Paul Ehrlich in 1885, involved the immersion of freshly removed tissue in methylated blue. In 1960, Suggestion was that TB may stain malignant epithelia of the mucous membrane in vivo, whereas normal tissue failed to retain the dye. TB was first applied for in vivo staining by Reichart in 1963 for uterine cervical carcinoma in situ [6].

Chemistry: Also known as Tolonium chloride, methylanaline aminotoluene which belongs to Thiazine group, which is partially soluble in water and alcohol.

TB is an acidophilic metachromatic dye, that selectively stains acidic tissue components ( sulfates, carboxylates and phosphate radicals). TB has affinity for nucleic acids and therefore binds to nuclear material of the tissues with high DNA and RNA content with molecular weight of 305.84

Composition: $100 \mathrm{ml}$ of $1 \%$ TB contains $1 \mathrm{gm}$ of toluidine blue powder, $10 \mathrm{ml}$ of $1 \%$ acetic acid, $4.19 \mathrm{ml}$ of absolute alcohol and $86 \mathrm{ml}$ of distilled water, $\mathrm{pH}$ maintained at 4.5 .

Principle of staining: As the TB has affinity for nucleic acids, the principle is based on the fact that dysplastic and neoplastic cells contain quantitatively more nucleic acids than normal tissues. Also malignant epithelium may contain wider intracellular canals than that of normal epithelium, which may facilitate penetration of the dye .The other proposals about the uptake of TB in dysplastic and carcinomas include the high density of nuclear material, loss of cell cohesion and increased mitosis $[6,7]$.

Procedure:

- Rinse the mouth twice with water for 20 s to remove debris.

- Apply $1 \%$ of acetic acid for 20seconds to remove ropey saliva and then apply $1 \%$ toluidine blue either with cotton swab or can be given as rinse.

- Then, 2 rinses with $1 \%$ acetic acid are done to reduce the mechanically retained stain. Finally rinse the mouth with water. Then the color change is assessd [7].

Interpretation: Positive- dark royal blue; Doubtful- pale blue; Negative- no colour change Figure 1. 

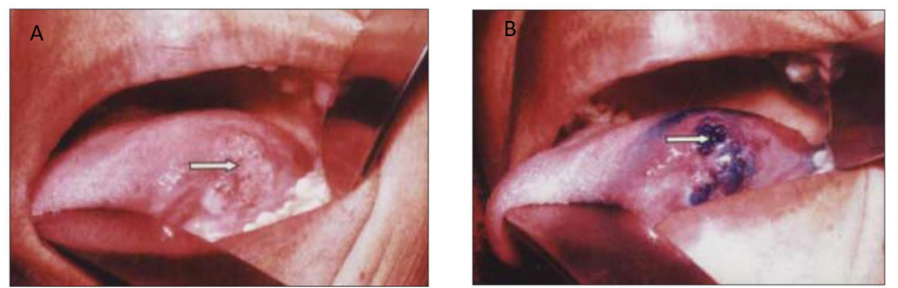

Figure 1: A. The lesion present over the lateral border of the tongue. B: lesion after staining with $1 \%$ toluidine blue [9].

False positive results are seen with following lesions: Epithelial hyperplasia, hyperkeratotic lesions, inflammatory and traumatic lesions, hyperplastic candidiasis can retain $60 \%$ of stain. The decision making can also be attributed to the experience of the clinician. Repeat the test after 10-14 days to allow the inflammatory lesions to resolve. This reduces the false positivity

False negative results are recognized in Low grade dysplasia, lichenoid reaction $[5,8]$.

\section{Advantages}

- It is inexpensive and simple procedure

- Can be used for screening high- risk patients who may have asymptomatic malignant lesions of oral cavity.

- Helpful for surgeon in operating room to evaluate free surgical margins.

- Toluidine blue staining of oral epithelium will not interfere with histologic staining or interpretation.

\section{Disadvantages}

- Both false positive and false negative results are more.

- Filiform papillae retain the dye due to high protein synthesis rate.

- TB appears to stain only three to four cells deep and thus reflects changes in the epithelial layer alone. Invaded underlying tissue is not penetrated by the dye. So the extent of submucosal spread is difficult to appreciate.

As the dye reacts with nucleic acid, there is a possible mutagenic effect of TB when vitally stained cells are exposed to high energy radiation $[8,9]$.

\section{Lugol's iodine(Li)}

Lugol's iodine was first made in $\mathbf{1 8 2 9}$, which is named after the French physician Lugol (1786-1851). Upto the end of 19th century, it was used as an antiseptic and disinfectant.

Other names for Lugol's solution are I2KI (iodinepotassium iodide), markodine, strong solution (systemic), aqueous iodine solution. In 1929, Schiller W described Iodine test to delineate areas of cervical pre cancers [10].

Composition: Iodine - 2 grams; Potassium iodide - 4 grams; Distilled water - $100 \mathrm{cc}$
Principle: Is based on glycogen content of the cytoplasm and the reaction is known as the iodine-starch reaction, visualized by a colour change. As there is enhanced glycolysis in cancer cells, do not promote the iodine-starch reaction. Hence it appears mustard yellow or saffron colour in dysplastic epithelium whereas normal epithelium appears mahogany brown colour due to high glycogen content. The vital dye with Lugol's solution is also called Schiller's test and during mucosal examination, Lugol's iodine is applied on the suspicious lesions $[5,11]$.

Procedure: Rinse with water/ carbocisteine syrup $250 \mathrm{mg} / 5$ $\mathrm{ml}$ and dry with a gauze to clear the mucin. Then apply Lugol's iodine until parakeratinized epithelium is stained a brown or black. After one to two minutes, interpret the stain reaction. Most effective method is to stain the lesion with 3\% Lugol's solution followed by $5 \%$ Lugol's solution. A study done by Nagaraju K (2010) [11] have used both toluidine blue and lugols iodine, showed that the combination can be used as a pretherapeutic assessment of biologic aggressiveness of lesions.

Interpretation: Normal mucosa-brown; Dysplastic mucosa- do not take up stain $[11,12]$ Figure 2.

\section{Methylene blue (Mb)}

In 1990, MB has been used to detect gastric, prostrate and bladder cancer. In the diagnosis, the accuracy of MB technique is used for identification of intestinal metaplasia, carcinoma or dysplasia.

The exact mechanism for the uptake of methylene blue in epithelial tissue may resemble that of toluidine blue in the acidophilic characteristic of cells with abnormal concentration of nucleic acid [14].

\section{Composition}

- Solution A: $1 \%$ methylene blue; $1 \%$ malachite ; $0.5 \%$ eosin

Glycerol \&dimethylsulfoxide.

- Solution B: Pre and post rinse solution had $1 \%$ lactic acid; Purified water.

Procedure: The application of methylene blue was as follows:

A 5-minute teeth brushing procedure is required before testing. Rinse the mouth with Bottle $\mathrm{B}$ for 20 seconds to remove food debris and excess saliva.
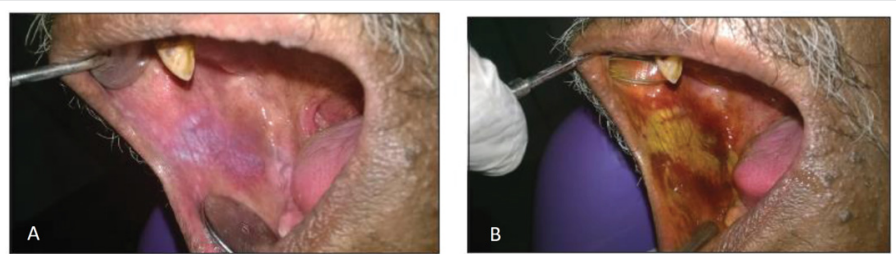

Figure 2: A: lesion present on the buccal mucosa.

$\mathrm{B}$ : lesion is stained with lugol's iodine solution. The margins appeared to be il defined shows prominent after staining [13].

Citation: Nitya K, Amberkar VS, Nadar BG (2020) Vital Staining- Pivotal Role in the Field of Pathology. Ann Cytol Pathol 5(1): 058-063. D0I: https://dx.doi.org/10.17352/ acp.000017 
The mucosa in the target area was gently dried with gauze and power air spray to ensure that the lesion is not contaminated with saliva. Gargle and rinse with $1 \%$ methylene blue dye (Bottle A) for 20 seconds, then expectorated. Then rinse again with Bottle $B$ for 20 seconds to wash out the excess dye Figure 3.

Interpretation: The pattern of dye retention- assessed by the intensity of stain retention on the lesion. Local, stippled, patchy and deep blue stains were marked as positive (+) reaction. Wide, shallow or faint blue stains were marked as negative $(-)$ reaction [13-15].

It plays a major role in demarcating the margins of lesion and thereby enabling clinician to estimate the correct size and extent of the lesion for proper management [15].

\section{Acetic acid staining}

In the past, $3-5 \%$ acetic acid was used as a vital staining for the detection of oral cancers in developing countries. Sankarnarayan, et al. [16], used 3\% acetic acid for the detection of cervical cancer, further Bhalang, et al. [17], used 5\% as a clinical marker for detection of oral cancer.

Composition: Of $1 \%$ acetic acid rinse $-1 \mathrm{ml}$ of glacial acetic acid and $99 \mathrm{ml}$ distilled water

Principle: Application of acetic acid causes reversible coagulation / precipitation of cellular proteins and causes swelling of the epithelial tissue, particularly abnormal squamous epithelial areas, dehydration of the cells and it helps in coagulating and clearing the mucous secretions.

The normal squamous epithelium appears pink and the columnar epithelium red, due to the reflection of light from the underlying stroma, which is rich in blood vessels. If the epithelium contains a lot of cellular proteins, acetic acid coagulates these proteins, which may obliterate the colour of the stroma.

The resulting aceto- whitening is seen distinctly as compared with the normal pinkish colour of the surrounding normal squamous epithelium [17].

Procedure: A piece of gauze soaked with $5 \%$ acetic acid is applied to a cleaned and dried lesion for 60 seconds.

After that gauze is removed and characteristic color change can be noted. Colorchange to opaque white is considered positive and transparent white as negative Figure 4 .
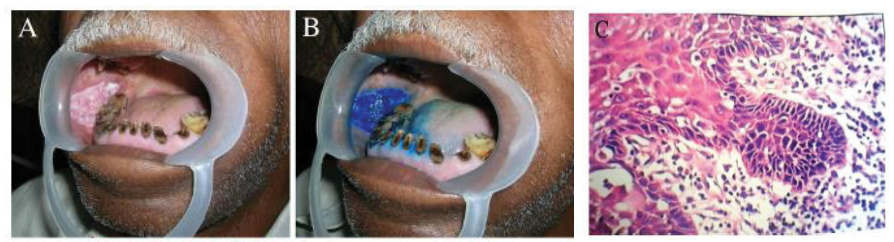

Figure 3: A: Lesion presenting clinically red and white homogenous patch.

B: Vital staining with Methylene blue showing deep staining

C: Histopathology image revealed severe dysplasia [14].

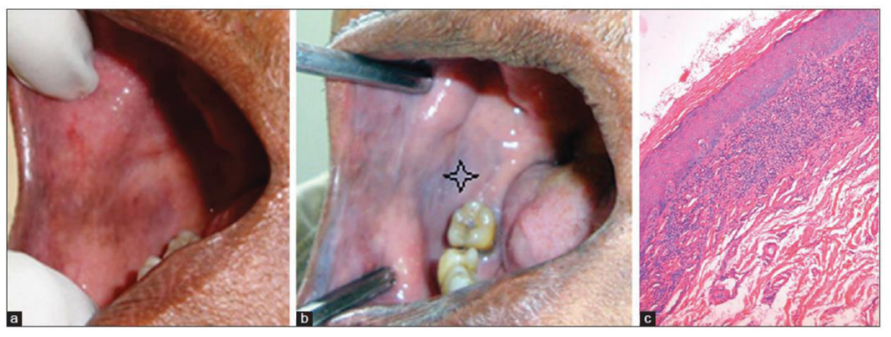

Figure 4: a: Patient with tobacco chewing habit. b: Application of acetic acid was done.

c: Histopathology revealed hyperkeratosis [18].

Advantages: Advantage is associated by false positive reaction with small aphthous-like ulcerated lesion that might not routinely be biopsied turned opaque white after the application of acetic acid and the histopathologic result was moderate epithelial dysplasia.

Disadvantages: Burns the oral mucosa

False positive results: The acetowhite appearance is not unique to early cancer. It is also seen in other conditions when increased nuclear protein is present, as in immature squamous metaplasia, in healing and regenerating epithelium, inflammation and hyperkeratosis [18].

\section{Rose bengal stain(Rb):}

It is $4,5,6,7$ tetrachloro-2, 4, 5, 7 tetraiododerivate of fluorescein, that can stain the desquamated ocular epithelial cells. It was observed by Norn, that with an exposure for 1 second, RB predominantly stains the cell membranes. An increasing the concentration or time of exposure, it produces predominant nuclear staining. RB staining has been even used to delineate the extent of the corneal and conjunctival neoplasms. RB is also used to detect oral epithelial dysplasia and OSCC [19].

Norn established the concept that RB stains the cells, wherever there is poor protection of the surface epithelium by the preocular tear film. This concept has also been extended to the interpretation of other lesions, such as herpes simplex and zoster, dysplasias or squamous metaplasia of conjunctival squamous neoplasms. Mucus/ mucous layer may block the RB uptake. A primary epithelial abnormality i.e, dysplasia, metaplasia, virus infected cells or other forms of epithelial keratitis, can render the inability of epithelium to interact with the mucous layer, thus allowing the RB staining $[19,20]$.

Procedure: Distilled water is used to rinse the mouth for 1 minute in order to clean the lesions.

Apply RB solution with cotton with 2 mins. Again the distilled water is used to rinse the mouth for $1 \mathrm{~min}$ to remove excess stain

Interpretation: Pink- positive; no color change- negative Figure 5.

False negative results could be due to the late clinical expression of genetically induced changes in the cells

Citation: Nitya K, Amberkar VS, Nadar BG (2020) Vital Staining- Pivotal Role in the Field of Pathology. Ann Cytol Pathol 5(1): 058-063. D0I: https://dx. doi.org/10.17352/ acp.000017 


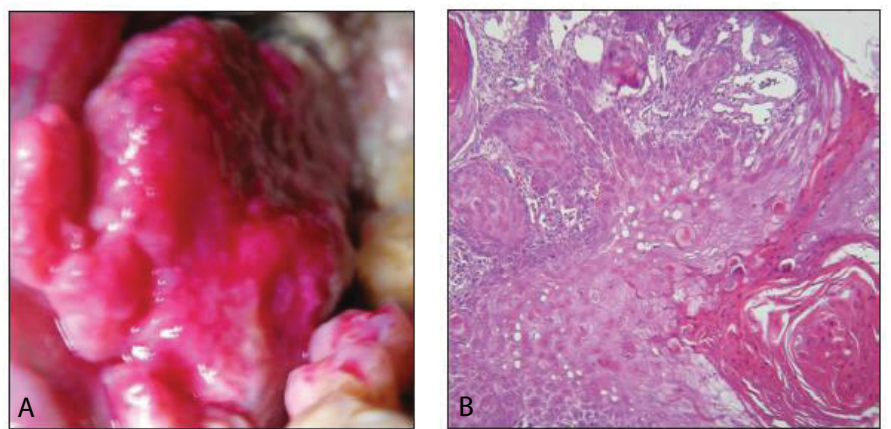

Figure 5: A. Intense positive staining with Rose Bengal stain in a malignant lesion B. Histopathology revealed Well differentiated squamous cell carcinoma [20]

or inability of the stain to penetrate the deeper layers of epithelium showing the dysplastic changes. Sensitivity-93.9\%, specificity-73.7\% and positive predictive value- $55.4 \%$.

A study done by Mittal $\mathrm{N}$ stated that RB staining is more promising in detection of dysplasia in precancerous or clinically benign lesions, when compared with toluidine blue because even the cases of mild dysplasia can be detected by RB staining [20].

\section{Supra vital stains}

Acridine orange: Acridine orange can be used as vital stain. It stains green for DNA, and orange for RNA under fluorescent microscopy. It also stains lysosomes [21].

DIOC stain for endoplasmic reticulum: It is a lipophilic carbocyanine dye, preferentially staining certain membrane structures in living cells.

It can be used to demonstrate the dynamics of endoplasmic reticulum. It works with living cells. Emission is at about $600 \mathrm{~nm}$ i.e. red colour [22].

Rhodamine 123 Fluorescence For Mitochondria: This is termed as a mitochondria specific dye, because this cationic cyanine dye is accumulated in electrically negative compartments. Such as mitochondria in healthy cells. The large membrane surface area in the mitochondrial matrix may contribute to the staining by binding large amounts of this fluorescent dye [23].

Nile red: This dye, which is hydrophobic, has been shown to be highly selective for lipid vesicles in cells. It stains lipid vesicles in the cell and gives red colour under flouro microscopy [23].

DAPI: This is used to stain DNA. It is 4,6-diamedine -2-phenylindole. It forms fluorescent complexes with AT-rich sequences of double-stranded DNA. It is widely used stable dye for DNA. The absorption maximum is $344 \mathrm{~nm}$ and the emission maximum at $449 \mathrm{~nm}$ i.e. it emits blue colour under flouroscent microscope. It is especially use to stain fixed cells [22].

Hoechst 33342: It is Bisbenzimide H33342. It is a specific stain for AT-rich regions of double stranded DNA, like DAPI and flouroscent properties are similar to that of DAPI. This can be preferentially used with living, unfixed cells [22].

The absorption maximum is at $340 \mathrm{~nm}$ and the emission maximum is $450 \mathrm{~nm}$, which emits blue colour.

Advantages: It is quick and easy to use.

Biopsy can be avoided/not required in intra vital staining. It is a non-invasive procedure. It is inexpensive and can be used for screening oral cancers. Eg. Toluidine blue test and using lugol's solution for screening esophageal carcinomas through Chromoendoscopy.

It provides more cytological details of the cell, where specific organelles can be stained.

Disadvantages: Most of these stains are dyes and are extremely toxic, which can result in death, so it has to be diluted to a larger extent.

Some of the dyes like flourochromes are carcinogenic and mutagenic. So one should avoid breathing any of the powder or allowing it to come in contact with the skin while preparing the solutions.

Some vital dyes, like Tryphan blue stain clothes and skin for a long time. So care should be taken to avoid direct contact with the dye [24].

\section{Conclusion}

As the oral cavity is easily accessible for the physical examination, various non-invasive diagnostic methods can be done to increase the early identification thereby increasing thesurvival rate of patients. The early detection, which includes the screening of signs and symptoms will increase the probability of cure. And one such screening method is vital staining using various dyes that can be used even in mass screening is not much used in routine practice. Though there are various studies done using vital dyes, toluidine blue staining is most widely practiced in detecting oral potentially malignant lesions and malignancy. Thus, studies using other stains can be done further to know about its practical applications in various lesions.

\section{References}

1. Douglas $L$ (2015) Making oral cancer screening a routine part of your patient care Part 1. BDJ Team 2015: 15066. Link: https://go.nature.com/2BXYqeL

2. Lingen MW, Kalmar JR, Karrison T, Speight PM (2008) Critical evaluation of diagnostic aids for the detection of oral cancer. Oral Oncol 44: 10-22. Link: https://bit.ly/2UArPC9

3. Patton LL, Epstein JB, Kerr AR (2008) Adjunctive techniques for oral cancer examination and lesion diagnosis: a systematic review of the literature. J Am Dent Assoc 139: 896-905. Link: https://bit.ly/3hfjUUt

4. Outline of methodology (1985) In: Culling CFA, Allison RT, Barr WT. Cellular pathology technique. 4th ed.Butterworth. London 15-26.

5. Bagalad BS, Mohan Kumar KP (2013) Vital Staining: Clinical Tool In Discovering Oral Epithelial Dysplasia And Carcinoma - Overview. J Dent Pract Res 1: 3438. Link: https://bit.ly/2XTuyZi 
6. Sudheendra US, Sreeshyla HS, Shashidara R (2014) Vital tissue staining in the diagnosis of oral precancer and cancer: Stains, technique, utility, and reliability. Clin Cancer Investig J 3: 141-145. Link: https://bit.ly/3dXuUE0

7. Sridharan G, Shankar AA (2012) Toluidine blue: a review of its chemistry and clinical utility. J oral Maxillofac Pathol 16: 251-255. Link: https://bit. ly/3hjXAZN

8. Su WW, Yen AM, Chiu SY, Chen TH (2010) A community-based RCT for oral cancer screening with toluidine blue. J Dent Res 89: 933-937. Link: https:// bit.ly/2XUs514

9. Hegde MC, Kamath MP, Shreedharan S, Dannana NK, Raju MR (2006) Supravita staining : It's role in detecting early malignancies. Indian $\mathrm{J}$ Otolaryngol Head Neck Surg 58: 31-34. Link: https://bit.ly/2MKTfkq

10. Petruzzi M, Lucchese A, Baldoni E, Grassi FC, Serpico R (2010) Use of Lugol's iodine in oral cancer diagnosis: An overview. Oral Oncol 46: 811-813. Link: https://bit.ly/3cUkval

11. Nagaraju K, Prasad S, Ashok L (2010) Diagnostic efficiency of toluidine blue with lugol's iodine in oral premalignant and malignant lesions. Indian J Dent Res 21: 218-223. Link: https://bit.ly/2BOHvaM

12. Xiao T, Kurita H, Shimane T, Nakanishi $Y$, Koike $T$ (2013) Vital staining with iodine solution in oral cancer: lodine infiltration, cell proliferation, and glucose transporter 1. Int J Clin Oncol 18 :792-800. Link: https://bit.ly/3e4KFc8

13. Fatima S, Basu R, Hallur NH (2016) Lugol's iodine identifies dysplastic tissue in precancerous lesions: A clinical trial. Ann Maxillofac Surg 6: 172-174. Link: https://bit.ly/2BXZoYr

14. Akthar R, Balasundhari S, Mala K, Natarajan S (2013) Methylene Blue as an early diagnostic marker for oral precancer and cancer. Springer plus 1-5. Link: https://bit.ly/37lcSJc

15. Chen YW, Lin JS, Wu CH, Lui MT, Kao SY, et al. (2007) Application of in vivo stain of Methylene blue as a diagnostic aid in the early detection and screening of oral squamous cell carcinoma and precancer lesions. J Chin Med Assoc 70: 497-503. Link: https://bit.ly/2UylTJX
16. Sankaranarayanan R, Wesley R, Thara S, Dhakad N, Chandralekha B, et al (2003) Test characteristics of visual inspection with $4 \%$ acetic acid (VIA) and Lugol's iodine (VILI) in cervical cancer screening in Kerala, India. Int J Cancer 106: 404-408. Link: https://bit.ly/2XTuzwx

17. Bhalang K, Suesuwan A, DhanuthaiK, Sannikorn $P$, Luangjarmekorn $L$, et al. (2008) The application of acetic acid in the detection of oral squamous cell carcinoma. Oral Surg Oral Med Oral Path Oral RadiolEndol 106: 371-376. Link: https://bit.ly/3dTE04l

18. Vinuth DP, Agarwal P, Kale AD, Hallikeramath S, Shukla D (2015) Acetic acid as an adjunct vital stain in diagnosis of tobacco-associated oral lesions: A pilot study. J Oral Maxillofac Pathol 19: 134-138. Link: https://bit.ly/37kZhl9

19. Du GF, Li CZ, Chen HZ, Chen XM, Xiao Q, et al. (2007) Rose bengal staining in detection of oral precancerous and malignant lesions with colorimetric evaluation: A pilot study. Int J Cancer 120: 1958-1963. Link: https://bit. ly/30yuyzQ

20. Mittal N, Palaskar S, Shankari M (2012) Rose bengal staining- diagnostic aid for potentially malignant and malignant disoders: a pilot study. Ind J Dent Res 23: 561-564. Link: https://bit.ly/30ys04W

21. Jackson FJ (1961) Supravital Blood Studies, using Acridine Orange Fluoroscence. Blood 17: 643-649. Link: https://bit.ly/3dTTMwu

22. Crissman HA, Hoflant MH, Stevenson AP, Wilder ME, Tobert RA (1990) Supravital cell staining with Hoechst 33342 and DiOC5(3). Methods Cell Bio 33: 89-95. Link: : https://bit.ly/2MLhUpb

23. Darzynkiewicz Z , Coico LS, Melamed RM (1981) Cell Biology Increased mitochondrial uptake of rhodamine 123 during lymphocyte stimulation (flow cytometry/cycling-noncycling cells/supravital fluorescent probe. Proc Natl Acad Sci USA 78: 2383-2387.

24. Fedele S (2009) Diagnostic aids in the screening of oral cancer. Head Neck Oncol 30: 1-5. Link: https://bit.ly/2UBhaqZ
Discover a bigger Impact and Visibility of your article publication with Peertechz Publications

\section{Highlights}

* Signatory publisher of ORCID

- Signatory Publisher of DORA (San Francisco Declaration on Research Assessment)

* Articles archived in worlds' renowned service providers such as Portico, CNKI, AGRIS, TDNet, Base (Bielefeld University Library), CrossRef, Scilit, J-Gate etc.

* Journals indexed in ICMJE, SHERPA/ROMEO, Google Scholar etc.

* OAI-PMH (Open Archives Initiative Protocol for Metadata Harvesting)

* Dedicated Editorial Board for every journa

* Accurate and rapid peer-review process

* Increased citations of published articles through promotions

* Reduced timeline for article publication

Submit your articles and experience a new surge in publication services (https://www.peertechz.com/submission).

Peertechz journals wishes everlasting success in your every endeavours.

Copyright: () 2020 Nitya K, et al. This is an open-access article distributed under the terms of the Creative Commons Attribution License, which permits unrestricted use, distribution, and reproduction in any medium, provided the original author and source are credited.

Citation: Nitya K, Amberkar VS, Nadar BG (2020) Vital Staining- Pivotal Role in the Field of Pathology. Ann Cytol Pathol 5(1): 058-063. D0I: https://dx.doi.org/10.17352/ acp.000017 